\title{
Paradoxical puborectalis contraction is a feature of constipation in patients with multiple sclerosis
}

\author{
Y W Chia, K P Gill, J S Jameson, A D Forti, M M Henry, M Swash, P J Shorvon
}

\begin{abstract}
Objective-To study the disturbed anorectal physiology associated with constipation in multiple sclerosis.

Methods-Anorectal function in 10 patients with clinically definite multiple sclerosis and constipation has been compared with 10 normal persons and 11 patients with idiopathic constipation, without multiple sclerosis.

Results-All 10 constipated patients with multiple sclerosis had difficulty evacuating barium paste during defaecography. In four of these there was complete failure of puborectalis relaxation when straining to defaecate, and in another four there was incomplete puborectalis relaxation. There was no evidence of lower motor neuron involvement of pelvic floor muscles in the multiple sclerosis group. Conclusions-Paradoxical puborectalis contraction is common in patients with multiple sclerosis in whom constipation is a symptom. This may be a feature of the disturbed voluntary sphincter control mechanism, analogous to detrusor sphincter dyssnergia in the bladder.
\end{abstract}

$(\mathcal{F}$ Neurol Neurosurg Psychiatry 1996;60:31-35)

Keywords: anismus; constipation; pelvic floor disorders; sphincters; multiple sclerosis

Sullivan et al ${ }^{1}$ reported a $53 \%$ incidence of constipation in patients with multiple sclerosis, and Hinds ${ }^{2}$ noted an incidence of $43 \%$. However, the pathophysiology of constipation in this disorder is not well understood. Urinary retention in multiple sclerosis is often due to detrusor sphincter dyssnergia, ${ }^{3}$ and constipation or faecal incontinence is especially frequent in patients with multiple sclerosis with urinary dysfunction. ${ }^{4}$ We considered that constipation in multiple sclerosis could be due to rectoanal dysfunction causing outlet obstruction, thus resembling detrusor sphincter dyssnergia of the bladder outlet, occurring as a result of the CNS lesions in these patients. ${ }^{5-7}$ Idiopathic constipation is often associated with paradoxical contraction of the puborectalis during defaecation, resulting in anal outlet obstruction and repeated straining during attempted defaecation. This has been called anismus. ${ }^{8}$ Anismus may be associated with slow colonic transit, although most patients with anismus have normal gut transit times. ${ }^{9}$ Anismus also occurs in Parkinson's disease, when it may respond to treatment with dopaminergic medication. ${ }^{10}$ The aim of our investigation was to study the disturbed anorectal physiology associated with constipation in multiple sclerosis.

\section{Patients}

Ten patients (mean age 44 years) with clinically definite multiple sclerosis and constipation, nine of whom were women, were studied. These patients all had normal bowel function before developing multiple sclerosis. All also had concomitant urinary dysfunction with urge incontinence and corticospinal tract signs. Two were mildly disabled (Kurtzke disability status scale (DSS) 1.0-3.5), five were moderately disabled (DSS $4 \cdot 0-6 \cdot 0$ ), and three had severe disability (DSS 6.5-8.0). ${ }^{11}$

Ten non-constipated subjects (mean age 35 years), nine of whom were women, served as controls. Eleven patients with constipation but without multiple sclerosis (mean age 40 years), nine of whom were women, were also studied. In all the constipated patients, with or without multiple sclerosis, constipation was severe, exceeding the criteria of Turnbull $e t$ $a l,^{12}$ who defined constipation as less than three bowel movements per week and/or straining during more than $25 \%$ of defaecations. All the patients with constipation had been referred to one of us (MMH) for management.

\section{Methods}

Anorectal physiology studies and defaecography were performed in all the patients with multiple sclerosis and in all the constipated patients without multiple sclerosis. In the normal control subjects only anorectal physiology was performed. Colonic transit studies were carried out in seven patients with multiple sclerosis and in five non-multiple sclerosis constipated patients.

\section{ANORECTAL PHYSIOLOGY}

The following measurements were made:

\section{Anal manometry}

The functional anal canal length and the resting and maximal voluntary anal contraction pressures were measured. A closed, water filled system was used, consisting of a $4 \mathrm{~mm}$ diameter microballoon mounted on a polythene tube $2 \mathrm{~mm}$ in diameter, connected to a pressure transducer (Statham Instruments Inc, USA) and a pen recorder (Devices, London). A sta- 
tion pull through technique was used. The normal values for our laboratory are resting pressure $60-100 \mathrm{~cm}$ water and maximal voluntary contraction pressure double the resting pressure. ${ }^{13}$

\section{Pudendal nerve terminal motor latency (PNTML)}

A specially constructed finger stall, with stimulating electrodes mounted at its tip and recording electrodes mounted at the base, was connected to a standard EMG machine (MS6, Medelec, Woking). The pudendal nerve was stimulated transrectally at the level of the ischial spine on either side with a supramaximal stimulus of about $50 \mathrm{~V}$ and $0.1 \mathrm{~ms}$ duration. The mean normal value for our laboratory is $2(\mathrm{SD} 0 \cdot 2) \mathrm{ms}^{14}$

\section{Single fibre $E M G$}

A Medelec SFEMG needle was used to record 20 different consecutive motor unit potentials in the four quadrants of the external anal sphincter muscle. The fibre density, representing the packing density of muscle fibres innervated by a single motor unit, was calculated. The mean value for our laboratory for patients younger than 50 years is $1.5(0 \cdot 16) .{ }^{15}$

\section{Mucosal electrosensitivity (MES)}

This was tested using a probe with two platinum electrodes placed $1 \mathrm{~cm}$ apart at the tip of a 10 FG polyvinyl catheter graduated in centimetres. A constant current generator was used to deliver stimuli of $0 \cdot 1 \mathrm{~ms}$ duration at 5 $\mathrm{Hz}$, increasing in $0.1 \mathrm{~mA}$ increments until a threshold of sensation was perceived. The middle third of the anal canal and the rectum were assessed. The normal ranges for these regions in our laboratory are: anal $0-10.2 \mathrm{~mA}$; rectum 2-34 mA. ${ }^{16}$

\section{Rectal sensation}

A latex balloon inserted into the rectum and inflated slowly with $5 \mathrm{ml}$ increments of air. ${ }^{17}$ Records were made of the volumes required to give: (a) a constant sensation of fullness (normal range $0-40 \mathrm{ml}$ ); (b) the first sensation of desire to defaecate (normal range $24-98 \mathrm{ml}$ ); (c) the maximum tolerated volume (normal range $125-337 \mathrm{ml}$ ).

\section{DEFAECOGRAPHY}

With the patient in the left lateral position on

Table 1 Comparison of anorectal physiology variables of patients with multiple sclerosis with controls and non-multiple sclerosis constipated patients

\begin{tabular}{lccc}
\hline & $\begin{array}{c}\text { MS } \\
\text { mean (SEM) }\end{array}$ & $\begin{array}{l}\text { Control } \\
\text { mean (SEM) }\end{array}$ & $\begin{array}{l}\text { Non-MS } \\
\text { mean (SEM) }\end{array}$ \\
\hline RP (cm water) & $75(6)$ & $103(9)^{\star}$ & $80(7)$ \\
VCP (cm water) & $56(13)$ & $120(22)^{\star}$ & $94(7)^{\star}$ \\
TV (ml) & $50(27)$ & $32(23)$ & $69(18)$ \\
UV (ml) & $99(38)$ & $74(28)$ & $120(22)$ \\
MTV (ml) & $190(91)$ & $181(63)$ & $209(35)$ \\
AS (mA) & $5.95(0.65)$ & $4.59(0.52)$ & $7.38(1 \cdot 8)$ \\
RS (mA) & $23.5(4 \cdot 1)$ & $17.6(2 \cdot 1)$ & $19.3(1 \cdot 8)$ \\
R-PNTML (ms) & $2 \cdot 4(0 \cdot 2)$ & $2 \cdot 15(0 \cdot 1)$ & $2 \cdot 17(0 \cdot 1)$ \\
L-PNTML (ms) & $2.36(0 \cdot 14)$ & $1.99(0 \cdot 14)$ & $2 \cdot 13(0 \cdot 1)$ \\
Mean FD-AS & $1.67(0.12)$ & $1.54(0.05)$ & $1.52(0.08)$ \\
\hline
\end{tabular}

$\star \mathrm{P}<0.05$, Mann-Whitney $U$ test

$R P=$ Resting pressure; VCP = voluntary anal contraction pressure; $T V=$ rectal threshold vol ume; UV = urge threshold volume; $M T V=$ maximum tolerated rectal volume; $A S=$ anal sensory threshold; $\mathrm{RS}=$ rectal sensory threshold; PNTML = pudendal nerve terminal motor latencies; $\mathrm{R}=$ right; $\mathrm{L}=$ left; mean $\mathrm{FD}-\mathrm{AS}=$ mean fibre density in anal sphincter muscle. an $x$ ray imaging table $20 \mathrm{ml}$ of barium paste was introduced to coat the rectal mucosa. This was followed by more barium paste until a sensation of rectal fullness was reported. Barium generally filled the rectum and the distal sigmoid colon. A contrast soaked tampon demonstrated the position of the vagina in female patients. A dab of barium marked the external anal orifice. The patient was then seated on a commode situated lateral to an image intensifier. Video imaging allowed dynamic evaluation of the events of defaecation. Static images were obtained at rest, on maximal voluntary contraction of the pelvic floor, on straining, and during defaecation. Supplementary posterior images were obtained if appropriate. ${ }^{812}$

\section{COLONIC TRANSIT STUDIES}

The patient ingested 20 small radio-opaque markers. A plain abdominal radiograph was taken 120 hours later. Retention of more than $20 \%$ of markers was taken to indicate slow transit. ${ }^{18} 19$

\section{STATISTICAL ANALYSIS}

The Mann-Whitney $U$ test was used to establish the significance of any differences between patients and normal subjects.

ETHICS

The research protocol was approved by the research ethics committee of the Central Middlesex Hospital, London. All investigations were carried out with written informed consent.

\section{Results}

Tables 1 and 2 summarise the results.

ANORECTAL PHYSIOLOGY

Although in the normal range, the mean resting anal canal pressure was slightly lower in the multiple sclerosis patient group and in the constipated patients without multiple sclerosis than in the control group $(P<0.05)$; there was no significant difference between the two groups. The mean maximal voluntary anal contraction pressure was lower in the multiple sclerosis group than in the non-multiple sclerosis constipated group and in the controls $(P<0.05)$. In four patients with multiple sclerosis the maximal voluntary contraction pressure was low. The rectal threshold, urge,

Table 2 Degree of puborectalis relaxation on straining as seen by defaecography, and colonic transit results in patients with multiple sclerosis

\begin{tabular}{lll}
\hline Patients & Puborectalis relaxation & Colonic transit \\
\hline 1 & Partial & Slow \\
2 & None & Slow \\
3 & None & Normal \\
4 & None & Normal \\
5 & Partial & Not done \\
6 & None & Slow \\
7 & Partial & Slow \\
8 & Complete & Slow \\
9 & Complete & Not done \\
& (has obstructing intra-anal & \\
10 & intussusception) & Not done \\
\hline
\end{tabular}




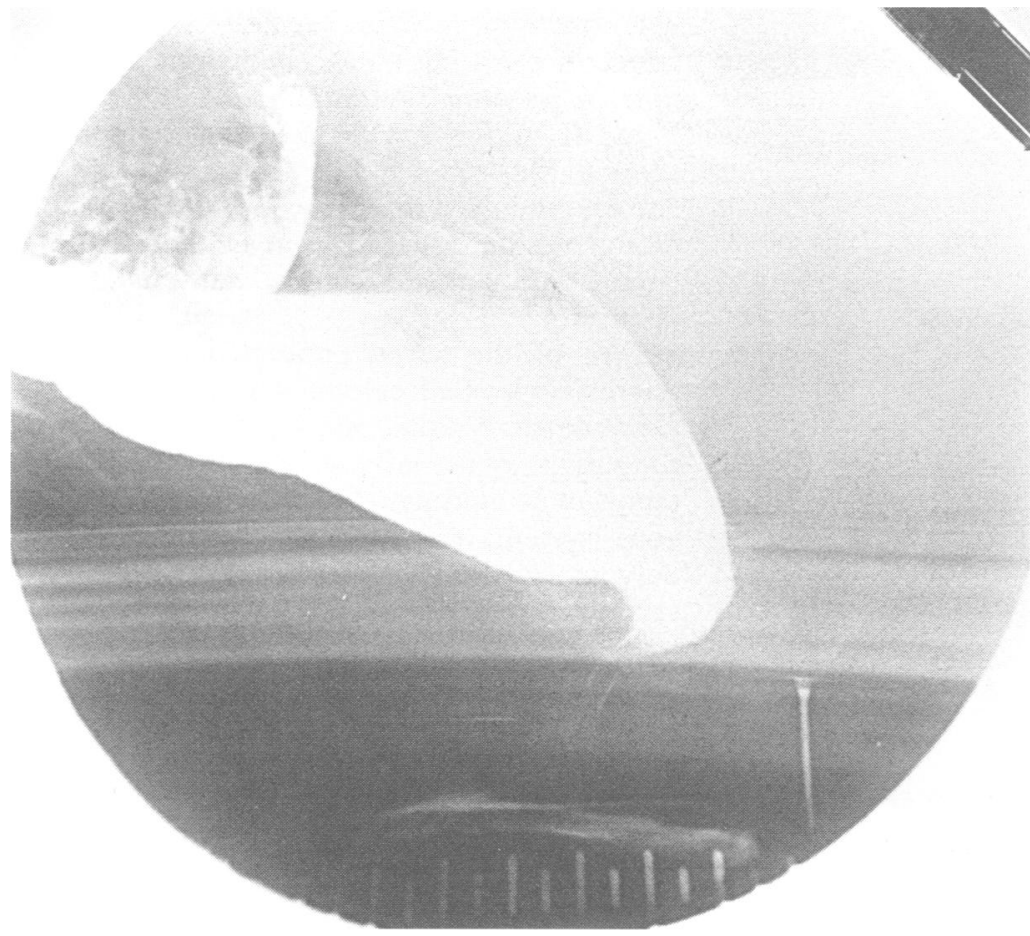

Figure 1 Defaecating proctography showing anorectal angle at rest.

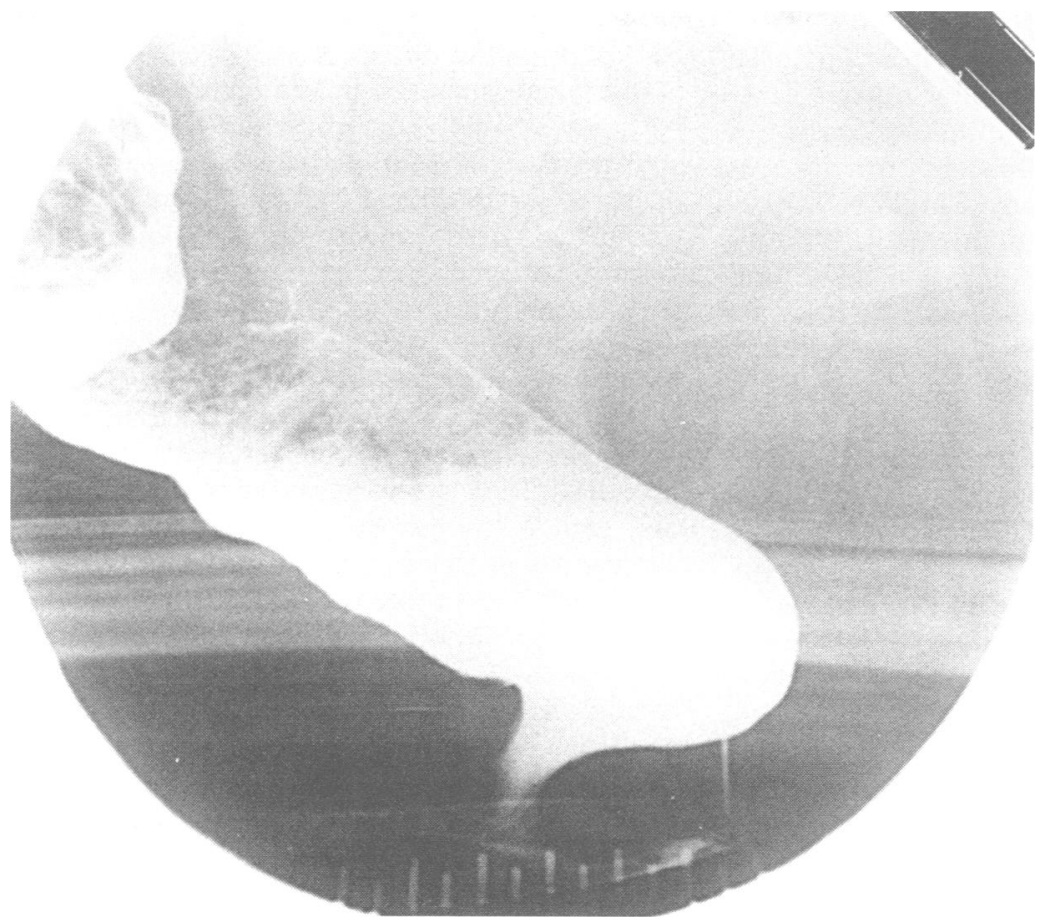

Figure 2 Defaecating proctography showing failure of puborectalis relaxation during straining to evacuate barium paste. sclerosis. In four of the patients with multiple sclerosis, however, the PNTML was increased on one side. Of these four patients, three had a raised fibre density in the external anal sphincter muscle, and these three also had low voluntary anal contraction pressures. Two other patients had raised fibre densities with normal PNTMLs. The mean fibre density of the external anal sphincter muscle in the multiple sclerosis group was not significantly increased compared with the controls and to the non-multiple sclerosis constipated group.

\section{DEFAECOGRAPHY}

All the patients with multiple sclerosis had difficulty evacuating barium. ${ }^{19}$ Four patients were unable to relax the puborectalis muscle when straining to defaecate (figs 1 and 2). Two of these patients used rectal digitation to facilitate defaecation, one required glycerine suppositories, and the other regular tap water enemas. Two patients with multiple sclerosis had incomplete puborectalis relaxation when straining to defaecate, and two seemed unable to generate a full straining effort, as shown by lack of pelvic floor movement, until external abdominal pressure was applied. Only two patients with multiple sclerosis showed normal puborectalis relaxation and normal defaecation. One patient developed an intra-anal intussusception during straining that obstructed defaecation (fig 3); she could only evacuate following reduction of the intussusception by patting rapidly on her perineum. One patient was unable to raise her intraabdominal pressure sufficiently to initiate defaecation normally.

Of the 11 constipated patients without multiple sclerosis, three had failure of puborectalis relaxation during straining to defaecate, two had rectoceles, two had enteroceles, and one had a posterolateral pouch. The increased frequency of abnormality in the multiple sclerosis group was significant at the $\mathrm{P}<0.05$ level (Fisher's exact test).

\section{COLONIC TRANSIT STUDIES}

These were completed in seven patients with multiple sclerosis. Five had slow transit. In two of these $20 \%$ or more markers were still distributed through the whole colon 120 hours after ingestion. In three the markers were clustered mainly in the descending colon, sigmoid colon, and rectum. Two of the constipated patients without multiple sclerosis had slow transit constipation.

\section{Discussion}

Gastrointestinal dysfunction is common in patients with multiple sclerosis. Sullivan and Ebers ${ }^{1}$ reported a prevalence of $53 \%$ and Hind et $a l^{2}$ a prevalence of $43 \%$ in patients with multiple sclerosis. It has been suggested that rectoanal dysfunction, resulting in outlet obstruction, may be the mechanism of constipation in multiple sclerosis ${ }^{5-7}$ in the same way as poor bladder emptying may be caused by detrusor sphincter dyssynergia. ${ }^{3}$ Mathers et al noted a paradoxical increase in puborectalis 


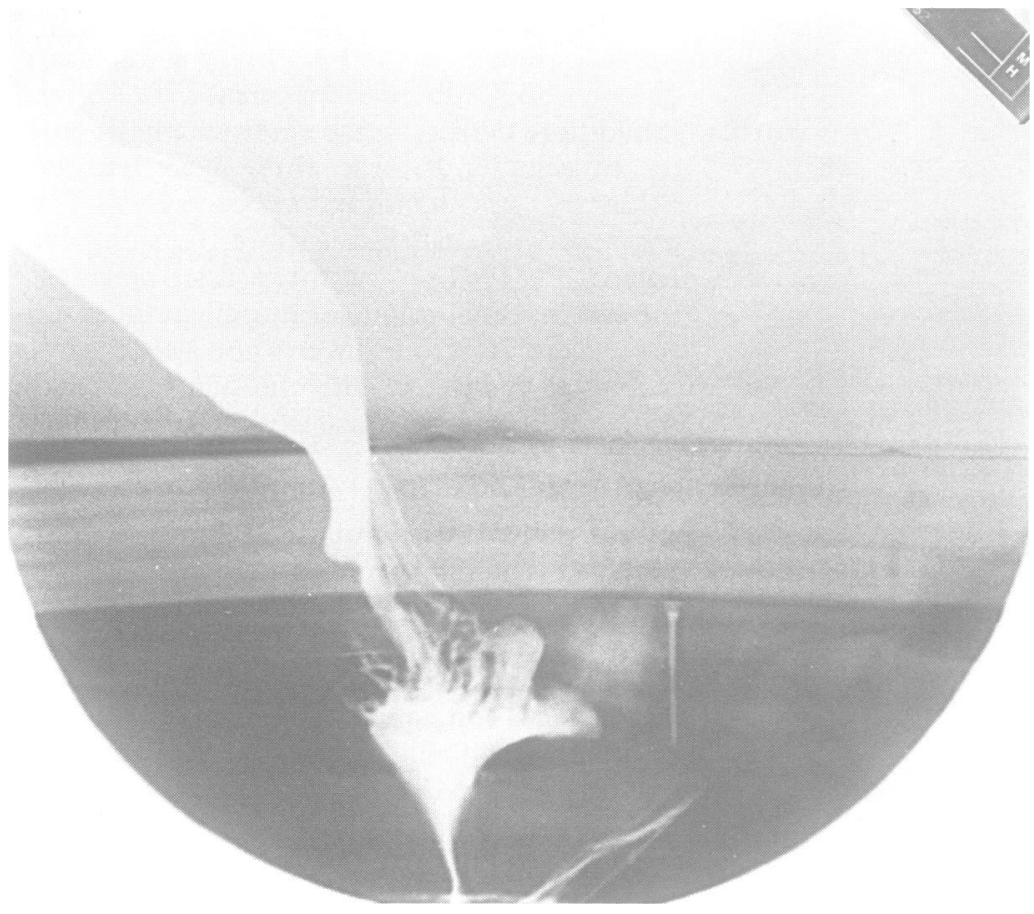

Figure 3 Defaecating proctography showing normal puborectalis effacement but with development of an intra-anal intussusception on straining to defaecate.

contraction during a defaecation strain in an EMG study of striated sphincter muscle function in five patients with multiple sclerosis. ${ }^{7}$ In three of these patients this abnormality was confirmed by defaecography. Similarly, Weber et al found that six of eight patients with multiple sclerosis with constipation had manometric abnormalities consistent with anal outlet obstruction. The role of paradoxical puborectalis contraction in idiopathic constipation has been evaluated in EMG studies. ${ }^{8-10} 20$

Eight of our 10 patients with multiple sclerosis and constipation had paradoxical puborectalis contraction or failure of this muscle to relax normally during a defaecation strain. These patients used various techniques to facilitate defaecation, including suppositories, enemas, and digital evacuation. None of these patients could completely empty their rectum, despite prolonged straining. Shorvon et al ${ }^{21}$ showed that puborectalis relaxation could properly be demonstrated only with the rectum filled with barium paste, and this was the technique we used.

The mean maximal voluntary contraction pressure was reduced in the multiple sclerosis group probably because there was impairment of the ability to contract this muscle as a result of the corticospinal lesion present in these patients. This suggestion is supported by the finding of a normal PNTML and normal fibre density in the external anal sphincter muscle in most of these patients, and by Mathers et $a l^{7}$ who reported an increased central motor conduction time to the external anal sphincter muscle, with normal PNTML, in patients with multiple sclerosis with incontinence or constipation. ${ }^{22}$ Despite this apparent weakness of the external anal sphincter muscle, however, none of the patients we studied had faecal incontinence, perhaps because of the dominance of constipation as a functional disorder in these patients. ${ }^{23} \mathrm{~A}$ combination of abnormal PNTML and increased fibre density found in some parous women with faecal incontinence and multiple sclerosis may be indicative of a double lesion, due to demyelination of the conus, and pudendal nerve damage due to childbirth. ${ }^{24}$

Five of the seven patients with multiple sclerosis who had colonic transit studies had slow transit. Colonic motility is a function of the activity of the intrinsic enteric nervous system, but is modulated by the autonomic nervous system, especially by parasympathetic nervous activity. For example, high cord transection results in decreased, and low cord transection in increased colonic motility. ${ }^{25}$ In studies of seven patients with multiple sclerosis and nine patients with complete cord transection $^{26}$ there was decreased colonic compliance and absence of the normal postprandial increase in motility. These observations are consistent with the notion that a CNS lesion, in or rostral to the thoracic cord, is a likely cause of constipation in patients with multiple sclerosis. Although this evidence suggests that incoordination of the puborectalis and external anal sphincter muscles during defaecation in patients with multiple sclerosis, leading to outlet obstruction and constipation, is due to a spinal lesion, understanding of its pathophysiology is incomplete. Mathers et al ${ }^{10}$ showed that this functional abnormality also occurred in Parkinson's disease, and that in Parkinson's disease it was responsive to dopaminergic medication, suggesting that it may result from more than one mechanism. De Groat et $a l^{27}$ showed that interruption of pathways in the spinal cord can result in detrusor sphincter dyssynergia, and it is therefore likely that paradoxical puborectalis contraction in multiple sclerosis is due to interruption of spinal pathways by demyelination. Treatment of this functional disorder remains an intractable problem. Specific measures to weaken the puborectalis muscle in idiopathic anismus type constipation by myotomy, ${ }^{28}$ or botulinum toxin injection ${ }^{29}$ have been disappointing, but biofeedback training has been helpful in some patients. ${ }^{30}$ The role of this treatment in patients with constipation associated with multiple sclerosis has not yet been explored.

1 Sullivan SN, Ebers GC. Gastrointestinal dysfunction in multiple sclerosis. Gastroenterology 1983;84:1640-6.

2 Hinds JP, Eidelman BH, Wald A. Prevalence of bowel dysfunction in multiple sclerosis: a population survey. Gastroenterology 1990;98:1538-42.

3 Petersen T, Pedersen E. Neurourodynamic evaluation of voiding dysfunction in multiple sclerosis. Acta Neurol Scand 1984;69:402-11.

4 Chia Y-W, Fowler CJ, Kamm MA, Henry MM, Lemieux M-C, Swash M. Prevalence of bowel dysfunction in patients with multiple sclerosis and bladder dysfunction. $f$ Neurol 1995;242:105-8.

5 Weber J, Grise P, Roquebert M. Radio-opaque marker transit and anorectal manometry in 16 patients with multiple sclerosis and urinary bladder dysfunction. Dis Colon Rectum 1987;30:95-100.

6 Glick ME, Hooshang M, Haldeman S, Bhatia NN, Bradley WE. Colonic dysfunction in multiple sclerosis. Gastroenterology 1982;83:1002-7.

7 Mathers SE, Ingram DA, Swash M. Electrophysiology of motor pathways for sphincter control in multiple sclerosis. F Neurol Neurosurg Psychiatry 1990;53:955-60. 
8 Preston DM, Lennard-Jones JE. Anismus in chronic constipation. Dig Dis Sci 1985;30:413-8.

9 Turnbull GK, Lennard-Jones JE, Bartram CI. Failure of rectal expulsion as a cause of constipation; why fibre and laxatives sometimes fail. Lancet 1986;i:767-9.

10 Mathers SE, Kempster PA, Law PI, Swash M, et al. Anal sphincter dysfunction in Parkinson's disease. Arch Neurol sphincter dysfunctio

11 Kurtzke JF. The disability status scale for multiple sclerosis; apologia pro DSS sua. Neurology 1989;39:291-303.

12 Turnbull GK, Bartram CI, Lennard-Jones JE. Radiological studies of rectal evacuation in adults with idiopathic constipation. Dis Colon Rectum 1988;31:190-7.

13 Henry MM, Snooks SJ, Barnes PRH, Swash M Investigation of disorders of the anorectum and colon. fournal of the Royal College of Surgeons of England 1985; 67:355-60.

14 Kiff ES, Swash M. Slowed motor conduction in the pudendal nerves in idiopathic (neurogenic) faecal incontinence. Br F Surg 1984;71:614-6.

15 Swash M. Electromyography in pelvic floor disorders. In: Henry MM, Swash M, eds. Coloproctology and the pelvic floor. 2nd ed. London: Butterworth-Heinemann, 1992: floor. 2 nd

16 Rogers J. Testing for and the role of anal and rectal sensation. In: Henry MM, ed. Clinical gastroenterology; anorectal tion. In: Henry MM, ed. Clinical gastroenterology; a
disorders London: Bailliere-Tindall, 1992:179-92.

17 Bartram CI, Mahieu C. Defaecography. In: Henry MM, Swash M, eds. Coloproctology and the pelvic floor. 2nd ed. London: Butterworth-Heinemann, 1992: 146-72.

18 Hinton JM, Lennard-Jones J, Young AC. A new method for studying gut transit times using radio-opaque markers. Gut 1969;10:842-7.

19 Gill KP, Chia YW, Henry MM, Shorvon PJ. Defecography in multiple sclerosis patients with severe constipation. Radiology 1994;19:553-6.
20 Kuijpers HC, Bleijenberg G. The spastic pelvic floor syndrome: a cause of constipation. Dis Colon Rectum 1985;28:669-72.

21 Shorvon PJ, McHugh S, Diamant NE, Somers S, Stevenson GW. Defecography in normal volunteers: results and implications. Gut 1989;30:1737-49.

22 Caruana BJ, Wald A, Hinds JP, Eidelman BH. Anorectal sensory and motor function in neurogenic fecal incontinence; comparison between multiple sclerosis and diabetes mellitus. Gastroenterology 1991;100:465-70.

23 Sorenson M, Lorentzen M, Petersen J, Christiansen J. Anorectal dysfunction in patients with urologic disturbances due to multiple sclerosis. Dis Colon Rectum 991;34:136-9.

24 Swash M, Snooks SJ, Chalmers DHK. Parity as a factor in incontinence in multiple sclerosis. Ann Neurol 1987; 44:504-8.

25 Connell AM, Frankel H, Guttman L. The motility of the pelvic colon following complete lesions of the spinal cord. Paraplegia 1963;1:98-115.

26 Glick ME, Meshkinpour H, Haldeman S, Hoehler F, Downey N, Bradley WE. Colonic dysfunction in patients with thoracic spinal cord injury. Gastroenterology 1984; 86:287-94.

27 De Groat WC Central control of the lower urinary tract. In: Neurobiology of continence. CIBA foundation symposium 151. Chichester: John Wiley, 1990:32.

28 Kamm MA, Hawley PR, Lennard-Jones J. Lateral division of the puborectalis muscle in the management of severe constipation. Br f Surg 1988;75:661-3.

29 Hallan RI, Williams NS, Melting J. Treatment of anismus in intractable constipation with botulinum A toxin. Lancet 1988;ii:714-7.

30 Bleijenberg G, Kuijpers HC. Treatment of spastic pelvic floor syndrome with biofeedback. Dis Colon Rectum 1987; 30:108-11. 